\title{
Exploratory Analysis of Factors Influencing Ai-Enabled Customer Experience for E-Commerce Industry
}

\author{
Amisha Gupta, Rupanshi Toteja* and Yajas Gupta \\ Jagan Institute of Management Studies, Rohini, Delhi, India
}

\section{ABSTRACT}

AI is the talk of the town in which the customer is a king. This research investigates how the integration of Artificial Intelligence in online shopping on e-commerce platforms can lead to AI enable customer experience. It also aims to explore the factors affecting artificial intelligence-enabled customer experience. The study is proposing a model from trust commitment theory and service quality model. The author used exploratory factor analysis to extract the constructs contributing to each variable in the model. Data is collected through a self-designed questionnaire wherein 150 people were targeted out of which 112 responded but after cleaning the data, 109 were left. As part of the conclusion, the author made some suggestions and recommendations for E-tailers deploying AI in services provided to their customers.

\section{KEY WORDS: ARTIFICIAL INTELLIGENCE, CUSTOMER EXPERIENCE, E-COMMERCE, PERSONALIZATION, SERVICE} QUALITY.

\section{INTRODUCTION}

The copacetic relationship companies have with their clients only works if the customers get value. There is no selling here - only relevancy says Colson (Chief Algorithm Officer at Stitch Fix) Every brand, every organization at present is working hard to provide a better customer experience. According to Anand Rao, Global Artificial Intelligence lead at PWC says that their latest AI research reveals that $86 \%$ of businesses right now are enjoying the benefits of a better customer experience through AI (Forbes report, 2020). Companies leverage AI to find a much faster of coming to data-driven decisions to improve the experience of their customers (Ben Harell, CMO, Priceline).

Biosc Biotech Res Comm P-ISSN: 0974-6455 E-ISSN: 2321-4007

\section{crossef}

Identifiers and Pagination

Year: 2021 Vol: 14 No (5) Special Issue

Pages: 104-112

This is an open access article under Creative

Commons License Attribn 4.0 Intl (CC-BY).

DOI: $h$ ttp://dx.doi.org/10.21786/bbrc/14.5/21
Companies are making decisions that are supported by data and based on the preferences of customers. According to the BCG report (2017), it says that brands that provide personalized experiences by incorporating advanced technologies and tools like artificial intelligence are seeing revenue increase by $6 \%$ to $10 \%$ - two to three times faster than those who don't. From the above-mentioned reports, it is wise to say that the benefits of artificial intelligence are innumerable. Brands are focusing on the use of technology to get one step closer to the customers and literature is rich with the studies from the point of view of organizations deploying these technologies but there is a dearth of research on how customers perceive and think of AI initiatives while online shopping through E-commerce platforms.

Amidst Covid-19 breakdown, E-commerce has seen tremendous growth and people started buying online to avoid human contacts. Also, according to an article in Economics times retail by Bain \& Company, it is predicted that the Indian e-retail market will reach nearly 300-350 million shoppers over the next five years with online Gross merchandise value (GMV) will reach to $100-120$ billion dollars by 2025 . Artificial Intelligence is already embedded in E-commerce platforms; it becomes important to understand AI-enabled customer experience.

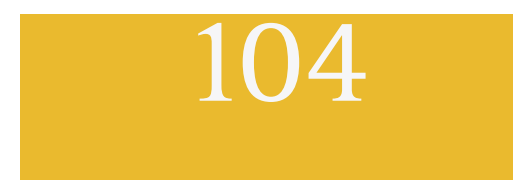


The finding of this research will help e-tailers to know and understand customer experience driven by artificial intelligence.

Literature Review: It is always the case that customer is at the center while designing any strategy. The predictive index and predictive science are all that the companies want, to upgrade customer and to ensure that customer is getting the best bang for the buck. Artificial Intelligence is the next generation technology disruption transforming how we live, interact and work. In the future, it is likely to substantially change both marketing strategies and customer behavior (Davenport.T 2020.) AI can possibly influence our lives decidedly. For purchasers, it can robotize dull errands and aid troublesome ones. For organizations, it can give a serious edge, separate items, and benefits, and even add to progress or failure (Jeffs. V, 2017).

Many researches have been conducted to understand the implication of the effects of AI-CRM on customer relationships and in particular the outcomes for customers and stakeholders (Libai.B, 2020). According to Salesforce, $84 \%$ of customers say the experience a company provides is as important as its products and services. Customers are the key to any business and researches are being conducted to understand how artificial intelligence tools can help in enhancing customer experience (Sujata.J 2019). AI will become the basis for customer personalization and the brands must utilize AI in their marketing (Pearson.A 2019). Also, Artificial Intelligence is revolutionizing the way customers interact with brands and studies are talking about AI-enabled customer experience in the context of online beauty (Ameen. N, 2021) and how retailers can have an advantage from it.

Most of the researches are from point of view of organization and companies deploying AI. There is a lack of empirical research to analyze and understand how the integration of AI in online shopping can lead to an AIenabled customer experience. There are fewer researches based on geography-India specific with compiled reference to E-commerce industry as Indian e-commerce will reach US\$ 99 billion by 2024, growing at a 27\% CAGR over 2019-24, with grocery and fashion/apparel likely to be the key drivers of incremental growth (IBEF report 2020) so there is a lot of scope for the study.

\section{RESEARCH METHODOLOGY}

A. Data: Data is collected through primary sources like self-designed questionnaire and expert interviews. For the primary survey, a convenience sampling method was used and the questionnaire was floated in the Delhi-NCR region.

B.Expert Interviews: Interviews of five experts belonging to artificial intelligence, customer relationship management, and digital marketing domains were conducted to know the practical applications of artificial intelligence in the E-commerce industry. Also, these interviews helped in drawing and better understanding the variables, which were already present in the literature. All of the experts agreed on the importance of convenience and personalization in providing a good customer experience. Customer centricity is keeping the customer at the center of everything while making any organizational decision and is achieved through the personalization factor.

While one of the experts was with the opinion that service quality matters a lot in building at par customer experience. For providing better service quality $4 \mathrm{E}$ method can be opted by companies which are Enable, Educate, Entice and Enforce (Behavior Change Theory). Furthermore, after deploying AI, companies should check the BIT score, which stands for Behavior, Interaction and Transactions score to understand which customer is likely to be valuable to the business. Satisfying the need of the customer is very important in E-commerce where your company's intervention is lesser means you are using artificial intelligence. The more value you add the more people will be happy from the platform. Moreover, one of the experts was with the opinion that gaining the trust of the customer with new technology (AI) where less human interaction is present becomes all the more crucial. Moreover, to reduce perceived sacrifice, chatbots should not ask mundane and repetitive questions from customers as the decrease in sacrifice will positively affect customer experience.

C. Variables: Personalization- Personalization is an interaction that empowers us to tailor client journeys and encounters according to the need and inclination of a particular client (Bilgihan, Kandampully, \& Zhang, 2016). It manages continuous individualization of a service/product to suit every guest's one-of-a-kind necessities and guides them through a custom conversion funnel. Zanker et al. (2019) described three dimensions of personalization in online services (i) user interface, (ii) content, and (iii) interaction process. These dimensions are further defined below:

i. User Interface- Personalization of the user interface alludes to the flexibility of the screen design and overall presentation, e.g., for differing screen sizes (Findlater \& Mc Grenere, 2020). Personalization has become an indispensable piece of planning an advanced framework because of the capacity to assemble an association with the end-user. The primary objective of personalization is to give a contextual experience by conveying substance and usefulness that line up with explicit user needs or interests with no specific effort from users.

ii. Content- Personalization of content alludes to the differentiation of data-dependent on an individual client's profile, including item or service contributions, and costs. Content personalization, the system for conveying pertinent and focused content dependent on what intrigues your crowd, is instrumental for connecting with clients on an individual level. Giving custom-made suggestions to clients is the contrast between deals and incredible deals. 
iii. Interaction Process- Personalization of the interaction process alludes to the self-rule of AI calculations to choose when and how to move toward clients

H 1a: Personalization has a positive direct impact on trust.

H 1b: Personalization has negative direct impact on perceived sacrifice.

H 1c: Personalization has a positive direct impact on relationship commitment.

Perceived convenience- Service convenience is defined as "the capacity to accomplish an errand in the briefest measure of time with minimal use of human energy" (Morganosky, 1986). Convenience in AI-Enabled e-commerce services means these are self-services that are available $24 \mathrm{X} 7$ and can be used from anywhere (Walch,2019).

\section{i. Time \\ ii. Location}

H 2a: Perceived convenience has a positive direct impact on trust.

H 2b: Perceived convenience has a negative direct impact on perceived sacrifice.

AI-enabled service quality- Artificial intelligence in customer service isn't just changing the customer's work yet, besides, improving customer dedication and its brand reputation. On account of the accessibility of apparatuses like artificial intelligence-fueled customer service bots, organizations in the $\mathrm{B} 2 \mathrm{C}$ business section are progressively entering a time of robotized customer service that is boosting the brand insight for customers. Earlier studies on self-service technologies show that customers evaluate service quality on the mentioned four aspects: (i) security, (ii) reliability, (iii) customer service, and (iv) interface design (Mckecnie, Ganguly, \& Roy, 2011; Wolfinbarger \&t Gilly, 2003).

i. Security- The quality of AI-enabled services depends to a huge extent on the amount and quality of personal information a brand can collect about customers. While much of this data is typically not sensitive, the amalgamation of seemingly non-sensitive personal information can result in an extensive user profile that, with insufficient security precautions, would enable fraudsters to create false identities (Cheatham et al., 2019).

ii. Reliability- Accepting a capacity for 'unbiased' customer interactions, Saratchandra (2019) says that artificial intelligence upgrades the reliability of customer services.

iii. Customer Service- Chatbots and other AI-helped client care apparatuses are progressively utilized as a computerized and possibly proficient method of improving the client journey (Treasure Data, 2019).

iv. Interface Design- Since numerous AI-empowered services depend on a self-service model, a carefully planned UI is frequently depicted as a basic success factor of such services. Indeed, AI can change the UI as it can handle all substance of the interface configuration including visual components, typography, movements, and graphical data (Irfan, 2020).

H 3a: AI-enabled service quality has a positive direct impact on trust.

H 3b: AI-enabled service quality has negative direct impact on perceived sacrifice.

Trust- An exemplary meaning of trust is a mentality of the sure assumption that one's weaknesses in a dangerous circumstance won't be misused. With regards to online commerce, this incorporates trusting the brand just as the innovation. With regards to AI, late investigations show that trust is a key in guaranteeing the acknowledgment, proceeding with progress, and improvement of this innovation and technology (Siau \&t Wang, 2018). The concept of trust is more intricate in the context of AIenabled customer service, where trust is not restricted to the technology and brand, but also the purpose and process of using AI (Hengster et al., 2016; Siau \&t Wang, 2018).

\section{i. Technology}

ii. Process-This dimension touches on the understandability of the technology. When algorithms and functional logics are explicit and clear, trust is likely to be strengthened (Lee \&t See, 2004).

iii. Purpose- The purpose shows faith in intentions (Hengster et al., 2016),

iv. Brand

H 4: Trust has a positive direct impact on AI-enabled customer experience.

Relationship commitment- Relationship commitment alludes to an undergoing aspiration to maintain an esteemed relationship with a brand (Moorman, Zaltman, Et Deshpande, 1992). Purchasers can turn out to be keener on associating with brands on the off chance that they experience positive connections and assemble solid relationships with them, which can lead them to be more dedicated towards these brands. Relationship commitment is a result of long-haul up to par interactions among customers and retailers (Wang et al., 2016). It guides clients to accept that there could be no other elective brands that would give comparable advantages, making them more averse to shop from elective brands. According to Gustafsson et al,.2005; Keiningham et al., 2017; Verhoef et al., 2009) researchers say that when communicating with brands, customers develop below mentioned three types of commitments: 
i. Affective commitment- Affective or emotional commitment refers to the emotional and personal involvement of customers that results in a higher level of trust and commitment (Gustafsson et al., 2005).

ii. Normative commitment- Normative or social commitment is based on subjective norms established over time, where customers feel that they ought to stay with a brand (Shukla et al., 2016).

iii. Calculative commitment- Calculative or functional commitment takes into account possible costs customers accrue by switching to another brand, which may be the result of a less attractive alternative brand or the absence of alternative brands (Shukla et al., 2016).

H 5: Relationship commitment has a positive direct impact on AI-enabled customer experience.

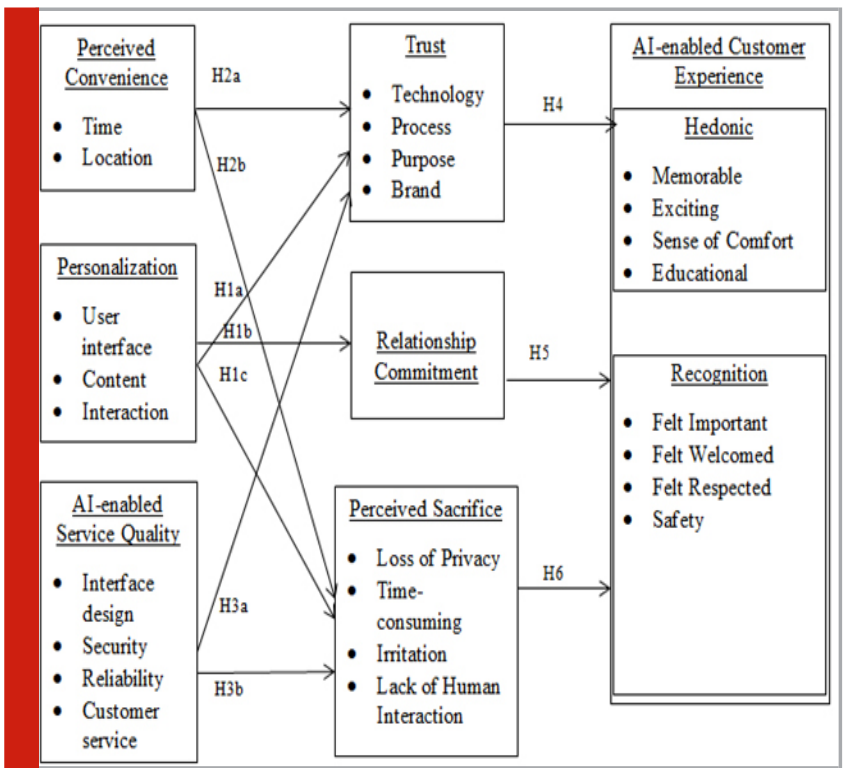

Table 1. Conversion of Likert Scale into Numerical Scale

\begin{tabular}{|l|c|c|c|c|c|c|c|}
\hline $\begin{array}{l}\text { Likert } \\
\text { Scale }\end{array}$ & $\begin{array}{c}\text { Strongly } \\
\text { Disagree }\end{array}$ & Disagree & $\begin{array}{c}\text { Somewhat } \\
\text { Disagree }\end{array}$ & Neutral & $\begin{array}{c}\text { Somewhat } \\
\text { Agree }\end{array}$ & Agree & $\begin{array}{c}\text { Strongly } \\
\text { Agree }\end{array}$ \\
\hline Number & 1 & 2 & 3 & 4 & 5 & 6 & 7 \\
\hline
\end{tabular}

Table 2. KMO and Bartlett's Test

\begin{tabular}{|l|c|c|}
\hline $\begin{array}{l}\text { Kaiser-Meyer-Olkin Measure } \\
\text { of Sampling Adequacy. }\end{array}$ & .848 \\
\hline Bartlett's Test of Sphericity & $\begin{array}{c}\text { Approx. Chi- } \\
\text { Square }\end{array}$ & 2970.182 \\
\cline { 2 - 3 } & $\mathrm{df}$ & 465 \\
\cline { 2 - 3 } & Sig. & .000 \\
\hline
\end{tabular}

Perceived sacrifice- Perceived sacrifice relates to "what is surrendered or sacrificed to acquire an item or service" and incorporates financial and non-money related expenses including time, exertion, intellectual commitment, or sentiments like aggravation and irritation (Zeithaml, 1988).

i. Time-consuming- Lack of human agents in AIempowered services may create a hitch for customers which may lead to customers spending more time in understanding and using the services. Clients may see this as a sacrifice, particularly those first-time clients (Gaurvit, 2019).

ii. Loss of privacy- AI-empowered services additionally requires individual information from buyers to work effectively, which can be seen as a further loss of privacy.

iii. Irritation- In the research of Andre et al., 2018, emphasized the need to explore sacrifices made by the customers while using automated services when limited numbers of options are present to choose from. The customers get irritated when they are not able to find the desired product.

iv. Lack of human interaction: As AI-enabled services consist of self-service, there is a lack of human interactions, and many studies highlight the importance of human interactions (Pham \& Ahammad, 2017).

H 6: Perceived sacrifice has a negative direct impact on AI-enabled customer experience.

Al-enabled customer experience: Customer experience alludes to the overall experience a customer has with a retailer, in light of their connections with and considerations about the brand(Oh, Teo, \& Sambamurthy, 2012). According to a study by Gartner,2020, the utilization of AI technologies, for example, AI, machine learning, and Natural Language Processing can help understand customer opinion and customer input at scale, accuracy, and speed not feasible through humans. This proposes that AI can possibly become one of the main tools for retailers to constantly improve the customer experience and along these lines to remain competitive (Newman, 2019).

AI-enabled customer experiences consist of hedonic and recognition aspects:

i. The hedonic aspect refers to memorable, exciting, comforting, educational, and novel experiences (Foroudi et al., 2018). 
ii. The recognition aspect refers to the feeling of importance, respect, being welcome, safety, relationship (Foroudi et al., 2018). In AI-enabled services, both hedonic and recognition aspects of the customer experience can be improved in terms of time, efficiency, enjoyment, and personalization (Saponaro et al., 2018).

Table 3. Communalities

My experience with E-Commerce platform has been memorable

I feel welcomed while using the E-Commerce platform

I feel important while using E-Commerce platform

I feel respected while using E-Commerce platform

I feel comfortable while using E-Commerce platform

I feel excited while using E-Commerce platform as it provides variety of offers and deals

I feel informed about the details of the product while purchasing it

I feel safe while making prepaid purchase while using E-commerce platform

I feel E-Commerce platforms are well designed and easy to use

I feel secure while entering my personal and payment details on E-Commerce platform

I can rely on E-commerce platform for fulfillment of my needs.

I feel chat bots and self-help customer service provide solutions as per my expectations.

It would be very hard for me to switch away from E-Commerce platforms even if I want to

I feel that my life would be affected in some way or the other if I switch from

E-Commerce platform

I feel that I am habitual of using E-Commerce platform that it would be costly for me

to switch from it.

I feel I have an emotional and personal attachment with E-Commerce platform

The performance of E-Commerce always meets my expectations

I feel that E-Commerce platforms have good features

I trust E-Commerce platform because they provide good quality products

E-Commerce platform shows interest in me as a customer

E-Commerce platform allows me to use the service whenever I choose

E-Commerce platform allows me to use the service at a convenient time

E-Commerce platform allows me to use the service wherever I choose

E-Commerce platform allows me to use the services from the comfort of home

I value E-Commerce platform as it adjusts itself according to the device I use

I value E-Commerce platform that acquires my personal preferences and personalize the services and products itself.

I value E-Commerce platform because they notify me about the offers and deals on the product I was searching for

Using E-Commerce is time consuming

I get annoyed while using E-commerce platform when I am not able to find desired product

I am concerned about the loss of privacy while using E-Commerce platform

I am concerned about the lack of human interaction while using E-Commerce platform

Extraction Method: Principal Component Analysis.

\begin{tabular}{|c|c|}
\hline Initial & Extraction \\
\hline 1.000 & .725 \\
\hline 1.000 & .823 \\
\hline 1.000 & .763 \\
\hline 1.000 & .772 \\
\hline 1.000 & .803 \\
\hline 1.000 & .813 \\
\hline 1.000 & .798 \\
\hline 1.000 & .673 \\
\hline 1.000 & .757 \\
\hline 1.000 & .820 \\
\hline 1.000 & .742 \\
\hline 1.000 & .671 \\
\hline 1.000 & .760 \\
\hline 1.000 & .834 \\
\hline 1.000 & .825 \\
\hline 1.000 & .755 \\
\hline 1.000 & .783 \\
\hline 1.000 & .788 \\
\hline 1.000 & .738 \\
\hline 1.000 & .678 \\
\hline 1.000 & .832 \\
\hline 1.000 & .925 \\
\hline 1.000 & .915 \\
\hline 1.000 & .893 \\
\hline 1.000 & .771 \\
\hline 1.000 & .886 \\
\hline 1.000 & .811 \\
\hline 1.000 & .689 \\
\hline 1.000 & .628 \\
\hline 1.000 & .656 \\
\hline 1.000 & .721 \\
\hline
\end{tabular}

Proposed Model \& Hypothesis Development: The model has been drawn from service quality model (Parasuraman et al., 1994) and trust commitment theory (Morgan \&t Hunt, 1994) to understand how the incorporation of AI-enabled tools and services can enhance the customer experience. The model has intermingled the factors that are pertinent to this study of customer experience with AI- enabled services. Moreover, perceived sacrifice and trust are considered as mediating variables in the model, wherein, personalization, service quality and perceived convenience are independent variables and the dependent factor is AI-enabled customer experience. Also, the model incorporates relationship commitment from trust-commitment theory to check its effect on AI-enabled customer experience.

\section{Proposed Model}

\section{Data Analysis \& Interpretation}

Measurement Scales: The measurement items (all statements) for all constructs were adopted from previous studies. Also, multiple items were used to measure each 
factor. For each item, a seven-point Likert Scale is used ranging from "Strongly Disagree to "Strongly Agree.
We have used EFA (Exploratory Factor Analysis) to explore the construct under each variable. PCA (Principal Component Analysis) method is used with Varimax Rotation.

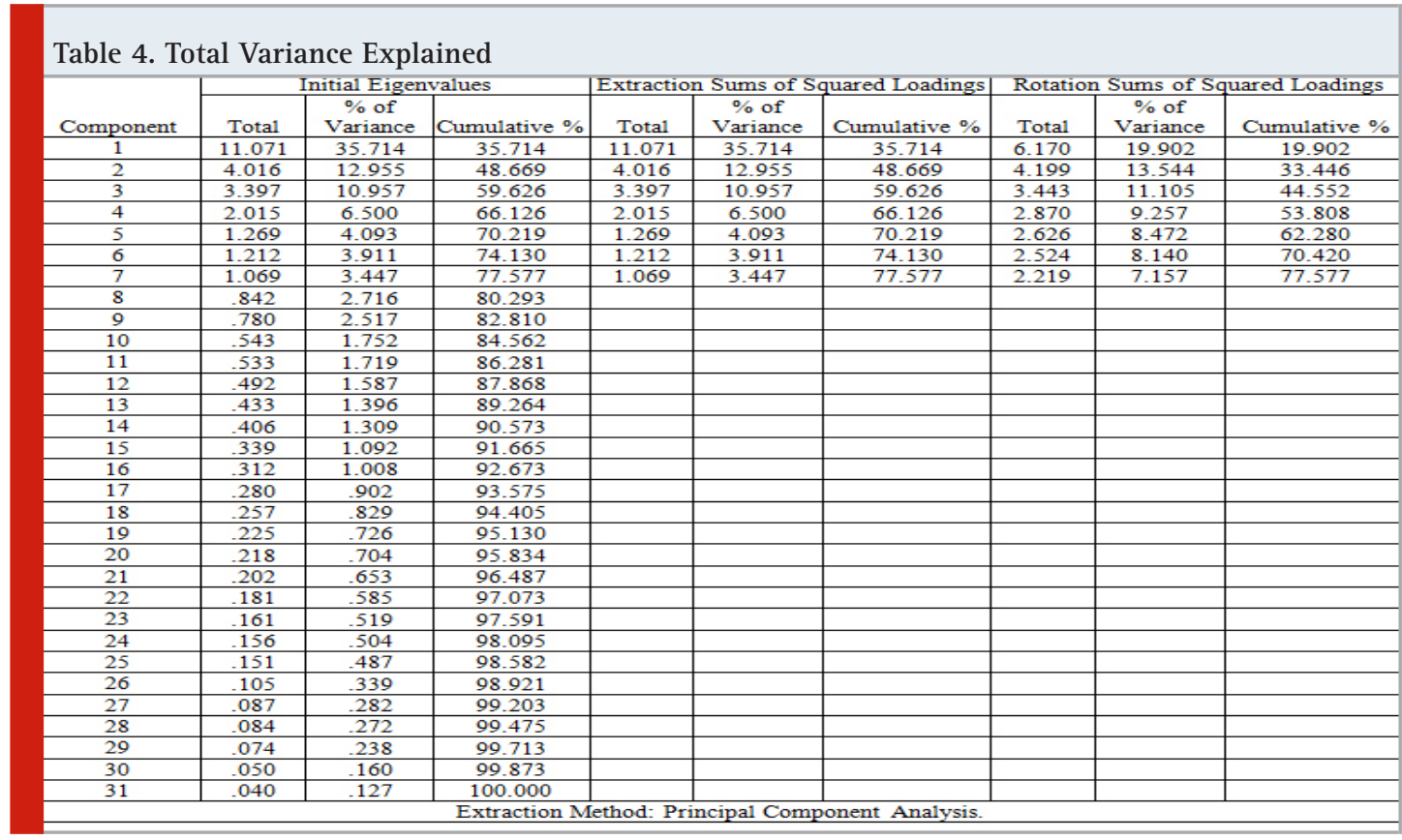

Table 5. Rotated Component Matrixa

1 I feel welcomed while using E-Commerce platform 2 I feel excited while using E-Commerce platform as it provides variety of offers and deals

3 I feel comfortable while using E-Commerce platform

4 I feel informed about the details of the product while purchasing it

5 I feel important while using E-Commerce platform

6 I feel respected while using E-Commerce platform

7 My experience with E-Commerce platform has been memorable

8 I feel safe while making prepaid purchase while using E-commerce platform

9 E-Commerce platform allows me to use the service at a convenient time

10 E-Commerce platform allows me to use the service wherever I choose

11 E-Commerce platform allows me to use the services from the comfort of home

12 E-Commerce platform allows me to use the service whenever I choose

13 I feel that I am habitual of using E-Commerce platform that it would be

costly for me to switch from it.

14 I feel that my life would be affected in someway or the other if

I switch from E-Commerce platform

15 I feel I have an emotional and personal attachment with E-Commerce platform

16 It would be very hard for me to switch away from

E-Commerce platforms even if I want to

17 I trust E-Commerce platform because they provide good quality products

18 The performance of E-Commerce always meets my expectations

19 I feel that E-Commerce platforms have good features

20 E-Commerce platform shows interest in me as a customer

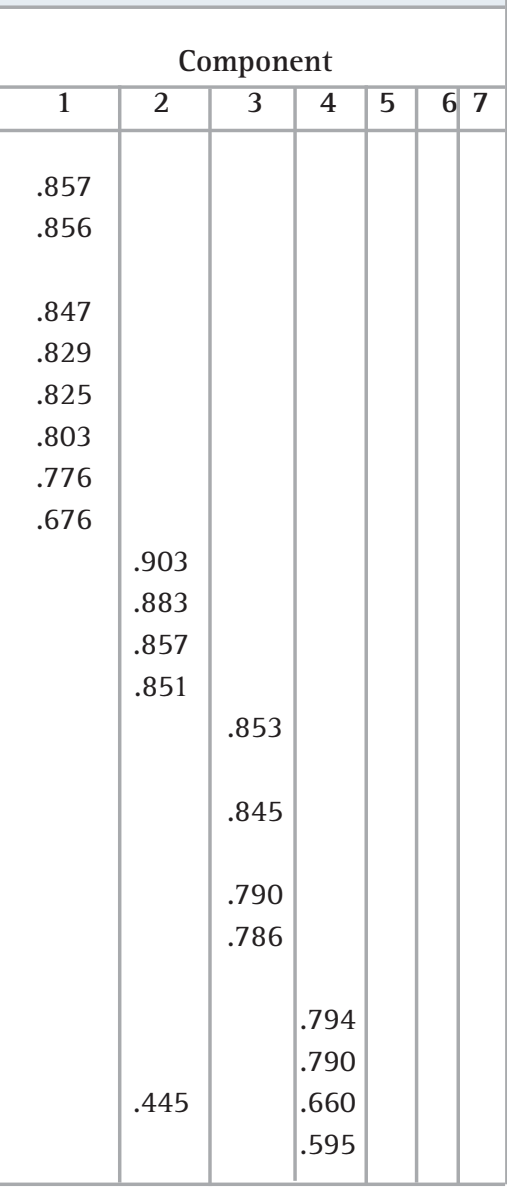


21 I feel secure while entering my personal and payment details on

E-Commerce platform

22.I feel chat bots and self-help customer service provide solutions as per my expectations.

23 I can rely on E-commerce platform for fulfillment of my needs.

24 I feel E-Commerce platforms are well designed and easy to use

25 I value E-Commerce platform that acquires my personal preferences and

personalize the services and products itself.

26 I value E-Commerce platform because they notify me about the offers and

deals on the product I was searching for

27 I value E-Commerce platform as it adjust itself according to the device I use

$28 \mathrm{I}$ am concerned about the lack of human interaction while using E-Commerce platform

.758

29 Using E-Commerce is time consuming

30 I am concerned about the loss of privacy while using E-Commerce platform

31 I get annoyed while using E-commerce platform when I am not able to find desired product

Extraction Method: Principal Component Analysis.

Rotation Method: Varimax with Kaiser Normalization. a

a. Rotation converged in 8 iterations.

Table 6. Reliability Statistics for Questionnaire

\begin{tabular}{|l|c|}
\hline Cronbach's Alpha & N of Items \\
\hline .900 & 31 \\
\hline
\end{tabular}

This test fulfills the assumption of KMO which needs to be more than 0.6 and here it is 0.848 which means that sample is adequate up to $84.8 \%$. Also, the significant value should be less than 0.05 and here $\mathrm{P}$-value is 0.000 which means the result is appropriate and normality is achieved. Now we will move ahead with communalities. The basic assumption about communality is that it should be more than 0.5 and in the below table it is achieved as all the values are above 0.5 .

The above table shows the total variance explained by the factors and it is 77.577 which is satisfactory. This states that $77.577 \%$ of variance is explained by mentioned 7 factors in the model. The above rotation component matrix shows the statements falling under which factors. The KMO value for each statement is near or more than 0.6 which fulfills the basic assumption. As from the table we can say that statements 1-8 come under factor 1 which is AI-enabled customer experience. Statements 9-12 fall under factor 2 which is AI-enabled service quality. Statements 13-16 contribute to factor 4 which is a Relationship commitment.

\begin{tabular}{|l|c|c|}
\hline Table 7. Reliability Results as per factors \\
\hline Factor & $\begin{array}{c}\text { No of Statement in } \\
\text { the Factor }\end{array}$ & $\begin{array}{c}\text { Cronbach's } \\
\text { Alpha value }\end{array}$ \\
\hline AI-enabled Customer Experience & 8 & 0.945 \\
\hline AI-enabled service Quality & 4 & 0.856 \\
\hline Relationship Commitment & 4 & 0.903 \\
\hline Trust & 4 & 0.869 \\
\hline Perceived Convenience & 4 & 0.964 \\
\hline Personalization & 3 & 0.898 \\
\hline Perceived Sacrifice & 4 & 0.729 \\
\hline
\end{tabular}

Now the statement 19 comes under Factor 2 with KMO .445 and Factor 4 with KMO .660 we will consider statement 19 into factor 4 based on KMO assumption so statements 17-20 fall under factor 4 that is Trust. Now Factor 5 which is Perceived Convenience consists of statements 21-24. with satisfactory KM0 values. Factor 6 is Personalization and it consists of 3 statements which are 25, 26 and 27 statements with KMO above 0.6. Again, the statement 30 falls under Factor 2 and Factor 7, based on KMO value which needs to be more than 0.6 , we will put the statement under Factor 7 which is Perceived Sacrifice. So from this table, we can get the statements and appropriate factors, and all the hypotheses and criteria are met. 
Reliability Analysis: For checking, the reliability of the questionnaire and reliability of each factor Cronbach's Alpha test is done.

From table 6, the Cronbach's Alpha value is 0.9 , so we can say that the questionnaire is reliable.

From table 7, Combined Cronbach's Alpha for each variable is more than 0.7 , which means that all the variables and contributing statements are reliable.

\section{FINDINGS \&t CONCLUSION}

The findings show that two types of AI enable customer experience exists namely hedonic which includes memorable, exciting, sense of comfort and education in our context and other is the recognition which includes important, respect, welcome, and safety in our study. While retailers need to implement innovative technology, it is pivotal to understand how customers perceive the technology. The important points that can be concluded from the above study are that all the seven factors are reliable and all the statements are considered and extracted in EFA, so the model is the best fit and can be used by the E-Commerce industry. It also shows that although people have a concern about the loss of privacy still people are habitual of purchasing from E-Commerce platform and somehow that it would be difficult for them to switch from it to offline stores, so the E-tailers can come up with some measures for the privacy of customers so that they can get rid of their concerns. Also, customers get annoyed when they are not able to find their desired product, so the brands should come up with some features with the help of which customers could find their desired products easily.

Limitations and Future Research: This research only focused to explore and extract the factors under each variable that influences artificial intelligence-enabled customer experience in the E-commerce industry in Delhi-NCR, India. The study can be conducted in crossstates and cross-national contexts. The relationships and mediating effect is yet to be established and empirically verified, and the model is yet to be confirmed by using Confirmatory Factor Analysis through the software IBM Amos. Moreover, this study was e-commerce focused, so there is room to carry forward the research on different consumer segments which provide AI-enabled services and experiences. Also, the data that was left after cleaning was 109, so the future research can be carried by using a larger sample size to maximize the chance of generalizing the findings.

\section{REFERENCES}

AI Multiple. (2021, JANUARY 1). AI-powered CRM Systems in 2021: In-Depth Guide. Retrieved from AI Multiple: https://research.aimultiple.com/crm-ai/\#leadqualification

Ameen, N., Tarhini, A., Reppel, A., \&t Anand, A. (2020). Customer experiences in the age of artificial intelligence. Computers in Human Behavior, 1-14.
André, Q., Carmon, Z., Wertenbroch, K., Crum, A., Frank , D., Goldstein, W., .. Y Yang, H. (2017). Consumer Choice and Autonomy in the Age of Artificial Intelligence and Big Data. Customer Needs and Solutions, 28-37.

Babu, G., \&t Bhuvaneswari, T. (2012). A Data Mining Technique to Find Optimal Customers for Beneficial Customer Relationship Management. Journal of Computer Science, 89-98.

Bartlett, M., Brown, G., Duris, S., Lee, J., Smith, B., Akpata, H., . . . Thum, S. (2018). Artificial Intelligence (AI) An Introduction: What Every Customer Experience Professional Should Know. Thum, 1-19.

Daqar, M. A., \& Smoudy, A. K. (2019). The Role of Artificial Intelligence on Enhancing Customer Experience. International Review of Management and Marketing, 22-31.

Deb, S., Deb, V., \&t Jain, R. (2018). Artificial Intelligence Creating Automated Insights for Customer Relationship Management. CONFLUENCE, 1-7.

Emerson, S. (n.d.). 5 REASONS TO MAKE ARTIFICIAL INTELLIGENCE YOUR CRM'S PARTNER IN CRIME. Retrieved from Chetu: https://www.chetu.com/blogs/ technical-perspectives/crm-and-ai-integration.php

Gantz, J., Murray, G., Schubmehl, D., Vesset, D., \& Wardley, M. (2017). A Trillion-Dollar Boost: The Economic Impact of AI on Customer Relationship Management. IDC, 1-20.

Garcia, M. (2018). The potential of Data-Driven Virtual Assistants to enhance Customer Experience in the Telecommunications Industry. Human Factors in Design, 61-72.

Goldenberg, B. (2019, November 26). How AI Is Impacting CRM. Retrieved from Destination CRM: https://www. destinationcrm.com/Articles/Columns-Departments/ Customer-Experience/How-AI-Is-Impacting-CRM(Already)-135446.aspx

Hopkinson, P. J., \&t Singhal, A. (2018). Exploring the use of AI to manage customers' relationships. Academy of Marketing, 1-7.

KAPTURE . (2020, JANUARY 7). The Role of Artificial Intelligence in CRM. Retrieved from KAPTURE : https:// www.kapturecrm.com/blog/the-role-of-artificialintelligence-in-crm/

Kelley, L., Gilbert, D., \& Mannicom, R. (2003). How e-CRM can enhance customer loyalty. Marketing Intelligence \&t, 239-248.

Kumar, V., Rajan, B., Venkatesan, R., \&t Jim , L. (2019). Understanding the Role of Artificial Intelligence in Personalized Engagement Marketing. sage, 1-21.

Laaksonen, A. T. (2019). The use of artificial intelligence in customer relationship management. Jyväskylä: University of Jyväskylä, 1-33.

Libai, B., Bart, Y., Gensler, S., Kaplan, A., Kötterheinrich, K., Hofacker, C. F., \&t Kroll, E. B. (2020). Brave New World? On AI and the Management of Customer Relationships. Journal of Interactive Marketing, 1-13. Liew, A. (2008). Strategic integration of knowledge 
management and customer relationship management. Journal of Knowledge Management, 131-146.

MIT Technology. (2017). Customer Experience Meets AI. MIT Technology Review Custom.

Nguyen, B. (2011). The dark side of CRM. The Marketing Review, 137-149.

Pegasystems. (2017). Artificial Intelligence and Improving the Customer Experience. PEGA, 1-17.

Puntoni, S., Reczek, R., Giesler, M., \&t Botti, S. (2021). Consumers and Artificial Intelligence: An Experiential Perspective. Journal of Marketing, 131-151.

Reddy, K. (n.d.). Artificial Intelligence in CRM: What are the Benefits? Retrieved from wisestep: https://content. wisestep.com/artificial-intelligence-crm/

Roy, S. K. (2017). Constituents and consequences of smart customer experience in retailing. Technological
Forecasting and Social Change, 257-270.

Sales force. (2016). AI for CRM: A Field Guide to Everything You Need To Know. Salesforce, 1-32.

sen, A. k., dash, m., \&t Sinha, M. (2019). An Empirical study on AI and buyer experience - An Indian context. Journal of Information and Computational Science, 496-504.

Sharma, A. ( 2019, SEPTEMBER 17). How Artificial Intelligence is Transforming CRM Operations? Retrieved from signitysolutions: https://www.signitysolutions. com/blog/artificial-intelligence-transforming-crmoperations/

Taleb, N., Salahat, M., \& Ali, L. (2020). Impacts of BigData Technologies in Enhancing CRM Performance. 1-8.

Yao, M. (2017). Is Your Company Behind In Adopting A.I. For CRM? . Forbes. 